\title{
Asetosilasi Terpentin Indonesia Menggunakan Katalis Asam Sulfat
}

\author{
Diana $^{1)}$, Arief Budiman ${ }^{2)}$ \\ Jurusan Teknik Kimia, Fakultas Teknologi Industri, Universitas Islam Indonesia \\ Jalan Kaliurang KM 14,5, Yogyakarta, Indonesia ${ }^{1)}$ \\ Departemen Teknik Kimia, Fakultas Teknik, Universitas Gadjah Mada \\ Jalan Grafika 2, Yogyakarta, Indonesia ${ }^{2)}$ \\ E-Mail : diana@uii.ac.id ${ }^{l)}$
}

\begin{abstract}
Indonesia is one of the largest turpentine producing countries in the world. Turpentine is one type of essential oil whose main component is alpha pinene. Alpha pinene is a bicyclic terpene that can undergo various reactions. This research aims to study the reaction process of turpentine acetoxylation using sulfuric acid catalyst. The reaction is carried out using glacial acetic acid and acetic acid solution. The experiments were run in a batch reactor for 2 hours at a constant temperature. Samples are taken to be analyzed using gas chromatography $(G C)$. From the analysis it was found that the products included esters, isomers, and monocyclic alcohols. The use of acetic acid solution will significantly increase the monocyclic alcohol yield. The ratio of alpha pinene and acetic acid affects the conversion and product selectivity. While the purity of alpha pinen has no effect on the conversion achieved, but affects the selectivity of the resulting product.
\end{abstract}

Keywords: turpentine, acetic acid, acetoxylation, sulfuric acid

\section{Pendahuluan}

Terpentin adalah bahan baku terbarukan yang biasanya diperoleh dari getah pinus atau sebagai limbah dari proses Kraft. Di Indonesia, getah pinus dihasilkan dari jenis pinus merkusii. Terpentin didapatkan dari penyulingan getah pinus sebagai hasil atas sedangkan gondorukem merupakan hasil bawahnya. Gondorukem berupa padatan berwarna kuning jernih sampai kuning tua. Sedangkan terpentin berbentuk cair berwarna jernih agak kekuningan. Terpentin merupakan pelarut yang kuat sehingga biasa digunakan sebagai bahan pelarut dalam industri minyak cat (Sastrohamidjoyo, 2014).

Indonesia merupakan negara produsen terpentin terbesar ketiga setelah China dan Brasil. Saat ini, pengelolaan hutan pinus di Indonesia ditangani oleh PT Perhutani yang merupakan Badan Usaha Milik Negara dengan tugas menyelenggarakan perencanaan, pengurusan, pengusahaan dan perlindungan hutan. Terpentin merupakan salah satu produk unggulan non kayu PT Perhutani. Dari tiga wilayah kerjanya yaitu Jawa Tengah (unit I), Jawa Timur (unit II) dan Jawa Barat - Banten (unit III) dihasilkan terpentin 17.150 ton dengan luas hutan pinus sekitar 877.000 hektar (Perhutani, 2014). Produk terpentin sebagian kecil diolah oleh PT Perhutani Anugerah Kimia (anak perusahaan PT Perhutani) dan sisanya diekspor langsung dalam bentuk minyak terpentin (Wijayati, 2016).

Tabel 1 menampilkan komposisi umum terpentin Indonesia. Kandungan utama dari terpentin adalah alfa pinen yang memiliki struktur dua cincin sehingga disebut senyawa terpena bisiklik (Gambar 1). Struktur tersebut memungkinkan terjadinya berbagai macam reaksi, sehingga alfa pinen adalah senyawa yang potensial untuk diolah lebih lanjut menjadi berbagai produk turunan yang lebih berharga (Schwab dkk., 2013).

Alfa pinen dapat dipisahkan dari komponen lainnya dengan metode distilasi karena mempunyai perbedaan titik didih yang cukup besar. Namun karena senyawasenyawa tersebut mudah rusak pada suhu yang tinggi, sehingga perlu digunakan proses distilasi vakum untuk menurunkan titik didihnya. 


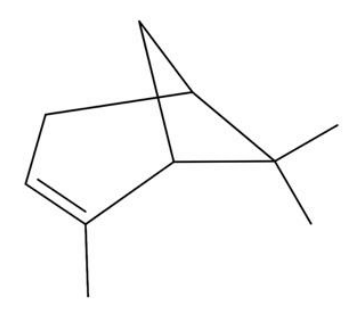

Gambar 1. Struktur Alfa Pinen

Tabel 1. Komposisi Terpentin Indonesia

\begin{tabular}{cc}
\hline Komponen & Kandungan \\
\hline Alfa pinen & $65 \%-85 \%$ \\
Camfen & $<1 \%$ \\
Beta pinen & $1 \%-3 \%$ \\
Caren & $10 \%-18 \%$ \\
Limonen & $1 \%-3 \%$ \\
\hline & (ntp.niehs.nih.gov)
\end{tabular}

Tabel 2. Titik Didih Senyawa Terpentin

\begin{tabular}{ccc}
\hline \multirow{2}{*}{ Komponen } & \multicolumn{2}{c}{ Titik didih $\left({ }^{\circ} \mathrm{C}\right)$} \\
\cline { 2 - 3 } & $760 \mathrm{mmHg}$ & $100 \mathrm{mmHg}$ \\
\hline Alfa pinen & 156 & 89 \\
Camfen & 158 & 91 \\
Beta pinen & 165 & 98 \\
Caren & 170 & 104 \\
Limonen & 177 & 110 \\
\hline & \multicolumn{2}{c}{ (Masten \& Haneke, 2002) }
\end{tabular}

Salah satu proses yang bisa dilakukan adalah isomerisasi alfa pinen menjadi camfen dan limonen. Kedua senyawa tersebut merupakan induk dari berbagai produk wewangian dalam kosmetik, parfum, maupun makanan. Proses lainnya adalah mereaksikan reaksi hidrasi alfa pinen yang akan membentuk senyawa alkohol monosiklik sebagai produk reaksinya. Selain itu, asetosilasi terpena adalah salah satu langkah sintesis penting dalam pembuatan ester terpenik yang bernilai tinggi untuk digunakan pada industri farmasi dan kosmetik (Thiel \& Hendricks, 2004).

Secara umum, asam homogen kuat banyak digunakan sebagai katalis dalam reaksi esterifikasi (Williams dan Whittaker, 1971). Namun penggunaannya menyebabkan pembuangan efluen menyebabkan masalah lingkungan. Masalah ini kemudian diatasi dengan penggunaan katalis heterogen. Beta zeolite (Gainsford dkk., 2001), ionic liquid (Liu, 2008), SBA 15 (Machado dkk., 2012) dan Amberlyst 70 (Golets dkk., 2012) telah digunakan untuk asetosilasi alfa pinena. Alfa pinen dikonversi menjadi terpinil asetat menggunakan zeolit H-beta dengan perbandingan $\mathrm{SiO}_{2} / \mathrm{Al}_{2} \mathrm{O}_{3}$ yang berbeda. Teramati bahwa laju reaksi alfa pinen berhubungan langsung dengan perbandingan $\mathrm{SiO}_{2} / \mathrm{Al}_{2} \mathrm{O}_{3}$ dalam zeolit. Alfa pinen diubah menjadi alfa terpinil asetat dengan yield $29 \%$ dalam satu langkah, dengan katalis zeolit $\mathrm{H}$ beta dalam asam asetat pada suhu ruang selama 24 jam. Ketika suhu reaksi meningkat, terlihat penurunan hasil dan selektivitas alfa terpinil asetat. Selama proses berlangsung, reaksi isomerisasi dan reaksi adisi ditemukan secara simultan dalam sistem. Bornil acetate adalah hasil utama jika menggunakan asam asetat glasial. Sedangkan penggunaan larutan asam asetat akan menghasilkan alfa terpineol sebagai produk utama (Yadaf, Patil \& Jasra, 2009). Asetosilasi alfa pinen juga dilakukan dengan menggunakan $\mathrm{H}_{3} \mathrm{PW}_{12} \mathrm{O}_{40}$, sebagai katalis. Asam heteropoli menunjukkan aktivitas katalitik yang jauh lebih tinggi daripada katalis padat asam konvensional seperti Amberlyst - 15 (Dutenhefner \& Silva, 2001).

Untuk mendapatkan konversi tinggi dalam reaksi antara alfa pinen dan asam asetat, diperlukan waktu yang lama, suhu dan tekanan tinggi, sedangkan selektivitas produk yang diperoleh rendah. Peningkatan suhu dan rasio asam asetat : alfa pinen akan meningkatkan hasil esterifikasi dan menurunkan produk isomerisasi (Swift, 2004)

Hidrasi alfa pinen yang dilakukan dengan katalis asam chlorida $(\mathrm{HCl})$ menghasilkan konversi alfa pinen yang mampu mendekati $100 \%$ pada menit pertama reaksi. Namun produksi $\alpha$-terpineol nya sangat minimum, sedangkan produk utamanya adalah bornil klorid. Produk lain yang dihasilkan adalah isomer-isomer alfa pinen dan yang paling utama adalah $\gamma$-terpinen dan limonen (Aguirre dkk., 2005) 
Pada percobaan tanpa katalis, reaksi antara alfa pinen dengan asam asetat dapat mencapai konversi alfa pinene sebesar $90,1 \%$ pada kondisi operasi tekanan 20 bar dan suhu $100^{\circ} \mathrm{C}$. Produk utama yang dihasilkan adalah terpinil asetat dan limonen. Dengan kondisi operasi yang sama, penggunaan katalis Ambelyst 70 akan mengkonversi $98,8 \%$ alfa pinen dan menghasilkan produk utama bornil asetat dan limonen (Golets dkk, 2012).

Penelitian lain melakukan isomerisasi alfa pinen dengan menggunakan katalis lempung clay yang diaktifasi sehingga terikat ammonia $\mathrm{NH}^{+}{ }^{+}$sebagai asam bronsted. Reaksi isomerisasi ini menghasilkan produk berupa camfen, limonen, terpinolen, terpene monocyclic dan bicyclic yang terdiri dari $\alpha$ terpinen, $\gamma$-terpinen, dan lain-lain. Reaksi dijalankan pada kisaran suhu $80-120^{\circ} \mathrm{C}$, dengan katalis $0,5 \%$ dan $1 \%$ berat. Total reaksi selama 3 jam. Disimpulkan bahwa reaksi berjalan secara paralel dan mengikuti reaksi order 1 (Grzona, 2005)

Sifat-sifat katalitik lempung asam montmorillonit termodifikasi, kaolinit (Mongolia) dan lempung (Belarusia), serta katalis alumino silikat komersial AS-36 dipelajari dalam isomerisasi alfa pinene dan 3carene pada fase cair. Konversi alfa pinene tertinggi didapatkan pada reaksi menggunakan montmorillonit yang diproses dengan 10\% $\mathrm{HCl}$ pada $90^{\circ} \mathrm{C}$. Keberadaan situs asam lemah dan menengah di tanah liat menghasilkan pembentukan camfen sebagai produk reaksi utama. Produk-produk reaksi adalah 2-caren, mentadiena, menthen, dan cymen. Jumlah mentadiena dalam campuran reaksi menurun sementara yang sebaliknya diamati untuk menthenes dan cymenes dengan peningkatan konsentrasi dan kekuatan dari asam (Sidorenko dkk., 2017).

Utami dkk (2011) melakukan pendekatan campuran heterogen non ideal untuk menyusun model kinetika hidrasi $\alpha$-pinene menjadi terpineol. Reaksi antara $\alpha$-pinene dengan air dijalankan menggunakan katalis chloro acetic acid. Asumsi yang diambil adalah: reaksi berlangsung di fase minyak, ketebalan lapisan film cairan sangat kecil sehingga reaksi terjadi di bulk dan minyak tidak mendifusi ke dalam air.

Penelitian hidrasi terpentin juga dilakukan dengan menggunakan makropori dan resin penukar kation asam kuat Amberlyst 15 wet sebagai katalis. Selama proses hidrasi, isomerisasi alfa pinen juga terjadi. Efek dari berbagai parameter seperti kecepatan pengadukan, jenis katalis, jumlah katalis, rasio massa reaktan, suhu dan penggunaan kembali katalis pada konversi terpentin dan hasil terpineol diselidiki untuk mendapatkan kondisi reaksi yang optimal dalam suatu reaktor tangki berpengaduk (Yang, dkk., 2011).

Dari penelusuran pustaka terlihat bahwa kajian mengenai konversi alfa pinen menjadi produk turunannya telah banyak dilakukan. Proses pemurnian alfa pinen dari terpentin harus dilakukan dengan distilasi vakum. Langkah ini merupakan sebuah proses yang boros energi. Penggunaan katalis padat pada reaksi asetosilasi hanya dapat menghasilkan konversi tinggi dalam waktu reaksi yang lama. Penelitian ini menggunakan asam sulfat sebagai katalis karena telah terbukti mampu menjadi katalis yang baik pada proses asetosilasi. Penelitian ini mempelajari penggunaan terpentin secara langsung sebagai bahan baku menggunakan katalis asam sulfat. Keberhasilan penelitian ini akan berguna untuk menyederhanakan tahapan proses dan mengurangi kebutuhan energi.

\section{Metodologi}

Bahan baku yang digunakan dalam penelitian ini adalah terpentin yang diperoleh dari PT Perhutani Anugerah Kimia. Dari hasil analisis didapatkan kadar alfa pinen dalam terpentin sebesar $83,5 \%$. Sebagai pembanding digunakan alfa pinen dengan kadar 98,5\% yang diperoleh dari PT Perhutani. Bahan lainnya adalah asam asetat glasial dan asam sulfat pekat (98\%). Eksperimen dilakukan menggunakan rangkaian peralatan seperti terlihat pada Gambar 2. Peralatan eksperimen berupa labu leher tiga yang dilengkapi dengan pemanas, pengaduk dan pendingin balik. Untuk mempertahankan suhu tertentu 
digunakan water bath, sedangkan pemanasan dan pengadukan dilakukan dengan hot plate magnetic stirrer.

Terpentin dan asam asetat dengan rasio tertentu dipanaskan dalam reaktor yang dilengkapi dengan pendingin balik sehingga mencapai suhu tertentu. Selanjutnya reaktan dan katalis dicampurkan dan waktu reaksi mulai dihitung. Ketika mencapai waktu tertentu diambil cuplikan untuk dianalisis dengan Gas Chromatography - Mass Spectrometry (GC/MS) dan atau GC untuk mendapatkan data konsentrasi senyawasenyawa hasil reaksi dan reaktan yang tersisa. Reaksi dijalankan hingga waktu tertentu yang diperkirakan telah tercapai kondisi konsentrasi produk yang tetap terhadap waktu reaksi.

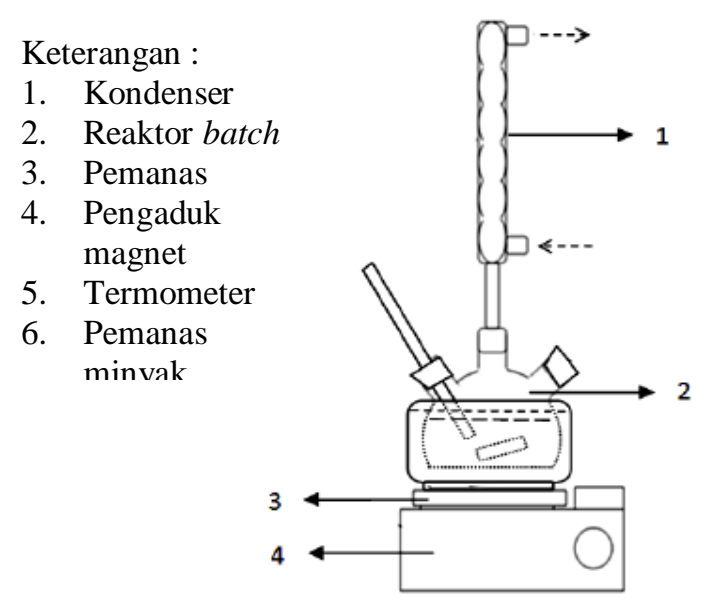

Gambar 2. Rangkaian Alat Eksperimen

Kemajuan reaksi dipantau dengan mengambil beberapa sampel pada interval waktu tertentu selama reaksi. Produk reaksi dianalisis dengan menggunakan gas kromatografi (GC) (Agilent Technologies, Model 7820A.) yang dilengkapi dengan kolom kapiler HP-5 (panjang $30 \mathrm{~m}$, diameter 0,32 mm dan ketebalan film 0,25 m) dan detektor FID. Nitrogen digunakan sebagai gas pembawa di GC dengan pengaturan suhu sebagai berikut: detektor dan port injeksi suhu $250{ }^{\circ} \mathrm{C}$, suhu kolom mulai $70-220^{\circ} \mathrm{C}$ dengan holding time 0,5 menit pada suhu awal dan heating ramp $20{ }^{\circ} \mathrm{C} /$ menit.
Analisis GC-MS dilakukan pada beberapa sampel untuk identifikasi dan analisis produk secara lebih detil. Setting untuk GC-MS diatur sama dengan setting untuk GC. Untuk analisis yang lebih tepat, dilakukan analisis GC untuk beberapa senyawa terpene dengan grade tinggi untuk digunakan sebagai standar.

Konversi alfa pinen (AP), selektivitas dan yield senyawa-senyawa produk (i) dihitung dengan persamaan berikut:

$\mathrm{X}(\%)=\frac{(\mathrm{GC} \text { area } \mathrm{AP})_{\mathrm{awal}}-(\mathrm{GC} \text { area } \mathrm{AP})_{\mathrm{akhir}}}{(\mathrm{GC} \text { area } \mathrm{AP})_{\text {awal }}} \times 100$

$\mathrm{S}_{\mathrm{i}}(\%)=\frac{\mathrm{GC} \text { area } \mathrm{i}}{(\mathrm{GC} \text { area } \mathrm{AP})_{\mathrm{awal}^{-}}(\mathrm{GC} \text { area AP })_{\text {akhir }}} \times 100$

$Y_{i}(\%)=\frac{X_{a p} S_{i}}{100}$

\section{Hasil dan Pembahasan}

Terpentin yang digunakan dalam eksperimen mempunyai kandungan alfa pinen sebesar $83,5 \%$. Selain itu juga dilakukan eksperimen menggunakan alfa pinen dari PT Perhutani yang mempunyai kemurnian 98,5\%. Sebagai pereaksi digunakan dua jenis asam asetat yaitu asam asetat glasial dan larutan asam asetat. Katalis yang digunakan adalah asam sulfat 33\%. Sebagai pembanding, juga dilakukan eksperimen tanpa menggunakan katalis (blanko). Percobaan dijalankan pada suhu $35^{\circ} \mathrm{C}$ yang dijaga konstan selama 2 jam dan hasilnya disajikan pada Tabel 3.

Dari hasil analisis GC terhadap produk reaksi, teridentifikasi keberadaan produkproduk ester yang terbentuk dari reaksi asetosilasi, seperti bornil asetat, terpenil asetat, dan lain-lain. Selain itu juga terdapat senyawa-senyawa camfen, limonen, terpinen, terpinolen yang merupakan produk reaksi isomerisasi alfa pinen, juga alkohol monosiklik seperti borneol dan alfa terpineol yang dihasilkan dari reaksi hidrasi. Hal ini menunjukkan bahwa reaksi antara terpentin dengan asam asetat berlangsung reaksi asetosilasi, isomerisasi, dan hidrasi secara simultan. Kondisi yang serupa juga terjadi pada penelitian yang dilakukan oleh Yadav 
dkk (2009) dengan skema reaksi seperti yang terlihat pada Gambar 3.

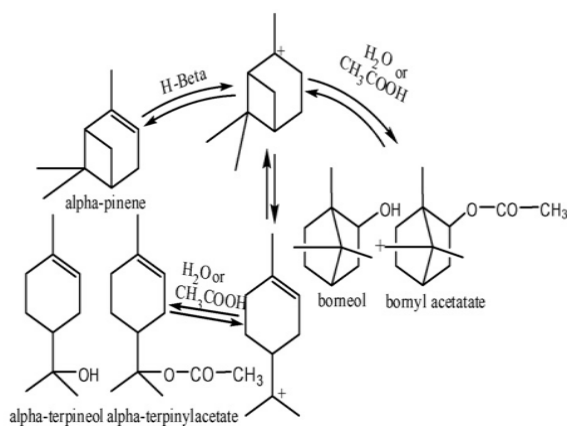

Gambar 3. Asetosilasi dan Hidrasi Alfa Pinen (Yadaf, 2009)
Pada reaksi-reaksi tanpa katalis, konversi yang dicapai sangat rendah. Penggunaan katalis asam sulfat mampu meningkatkan konversi secara signifikan, baik pada reaksi menggunakan terpentin maupun alfa pinen. Data pada Tabel 3 menunjukkan bahwa selektivitas isomer meningkat pada reaksireaksi yang menggunakan katalis $\mathrm{H}_{2} \mathrm{SO}_{4}$. Hal ini mengindikasikan bahwa katalis $\mathrm{H}_{2} \mathrm{SO}_{4}$ cenderung mengarahkan pada reaksi isomerisasi dibandingkan dengan adisi.

Tabel 3. Konversi dan Selektivitas Produk Pada Berbagai Variasi Jenis Reaktan

\begin{tabular}{rlrcrrrr}
\hline \multirow{2}{*}{ No } & \multirow{2}{*}{ Bahan Baku } & \multirow{2}{*}{ Asam Asetat } & \multirow{2}{*}{ Katalis } & \multirow{2}{*}{\begin{tabular}{c} 
Konversi \\
\cline { 6 - 8 } \cline { 5 - 7 }
\end{tabular}} & & & \multicolumn{3}{c}{ Selektivitas (\%) } \\
\hline 1 & Terpentin & Glasial & Blanko & 6,7 & 35,5 & 63,5 & 1 \\
2 & Alfa pinen & Glasial & Blanko & 7,1 & 40,2 & 58,8 & 1 \\
3 & Terpentin & Larutan & Blanko & 6,8 & 33,7 & 64,1 & 2,2 \\
4 & Alfa pinen & Larutan & Blanko & 7,7 & 37,2 & 60,7 & 2,1 \\
5 & Terpentin & Glasial & $\mathrm{H}_{2} \mathrm{SO}_{4} 33 \%$ & 88,5 & 14,7 & 83,5 & 1,8 \\
6 & Alfa pinen & Glasial & $\mathrm{H}_{2} \mathrm{SO}_{4} 33 \%$ & 88,7 & 20,3 & 77,7 & 2 \\
7 & Terpentin & Larutan & $\mathrm{H}_{2} \mathrm{SO}_{4} 33 \%$ & 93,3 & 11,2 & 69 & 19,8 \\
8 & Alfa pinen & Larutan & $\mathrm{H}_{2} \mathrm{SO}_{4} 33 \%$ & 96,2 & 15,6 & 61,3 & 23,1 \\
\hline
\end{tabular}

Jika direaksikan dengan asam asetat glasial, tidak ada perbedaan nyata pada capaian konversi dengan bahan baku terpentin $(88,5 \%)$ maupun alfa pinen $(88,7 \%)$. Namun jika direaksikan dengan larutan asam asetan, penggunaan terpentin sebagai bahan baku akan menghasilkan konversi sebesar 93,3\% sedangkan dengan alfa pinen mencapai $96,2 \%$.

Selektivitas produk alkohol meningkat drastis dengan penggunaan larutan asam asetat sebagai reaktan. Keberadaan air dalam larutan asam asetat menyebabkan terjadinya reaksi hidrasi secara masif membentuk alkohol monosiklik. Senyawa terbanyak yang terbentuk adalah alfa terpineol. Tiga reaksi (isomerisasi, asetosilasi, dan hidrasi) yang berlangsung secara simultan meningkatkan jumlah alfa pinen yang terkonversi. Selain itu, alfa pinen yang lebih murni akan meningkatkan kecepatan reaksi sehingga dapat mencapai konversi yang lebih tinggi.

\subsection{Pengaruh Waktu Reaksi}

Reaksi asetosilasi dijalankan selama 2 jam. Pada waktu tertentu diambil cuplikan sampel untuk dianalisis. Gambar 4 menampilkan konversi alfa pinen sepanjang waktu reaksi antara terpentin dengan asam asetat glasial menggunakan katalis asam sulfat.

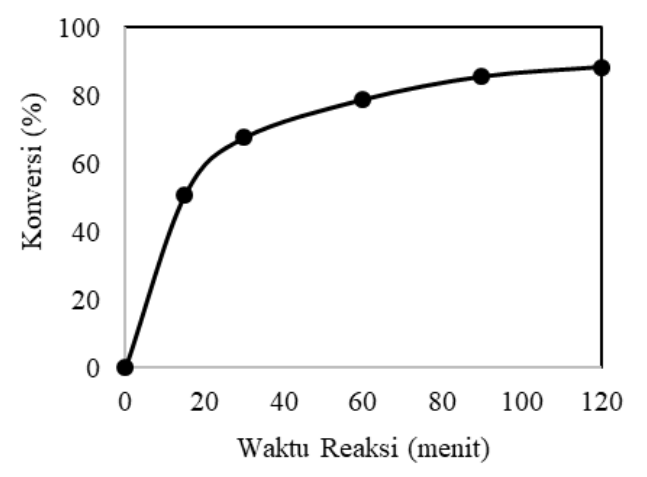

Gambar 4. Konversi Alfa Pinen Selama Waktu Reaksi 
Mula-mula reaksi berjalan dengan cepat dan mencapai konversi 50,8\% setelah reaksi berjalan selama 15 menit. Selanjutnya kecepatan reaksi semakin melambat dan setelah 2 jam didapatkan konversi akhir sebesar $88,5 \%$.

Kecepatan reaksi merupakan fungsi dari konsentrasi reaktan. Semakin lama reaksi berlangsung maka semakin banyak reaktan yang terkonversi sehingga konsentrasinya menurun. Pada kondisi ini diperlukan waktu lebih lama untuk mencapai konversi yang lebih tinggi.

\subsection{Pengaruh Rasio Reaktan}

Untuk mengetahui pengaruh rasio reaktan terhadap konversi dan hasil reaksi dilakukan percobaan menggunakan terpentin dan asam asetat glasial. Setiap mol alfa pinen memerlukan satu mol asam asetat untuk membentuk produk ester. Selain rasio stoikiometris dipilih rasio 0,5 untuk kondisi asam asetat berlebihan dan rasio reaktan 2 untuk kondisi alfa pinen berlebihan dan hasilnya ditampilkan pada Tabel 4, Gambar 5 dan Gambar 6.

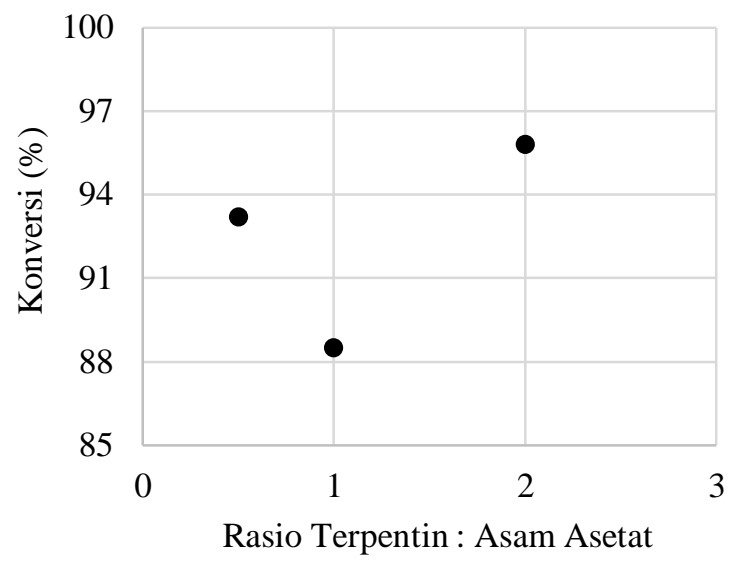

Gambar 5. Konversi Alfa Pinen pada Berbagai Rasio Reaktan

Reaksi yang dijalankan dengan salah satu reaktan berlebihan menghasilkan konversi yang lebih besar dibandingkan dengan reaksi yang dilakukan pada rasio stoikiometris. Dengan ekses asam asetat sebanyak 100\% konversi dapat ditingkatkan dari 88,5\% menjadi 93,2\%. Sedangkan kelebihan terpentin sebanyak $100 \%$ dapat menaikkan konversi menjadi $95,8 \%$.

Tabel 4. Reaksi Terpentin Dengan Asam Asetat Glasial Pada Berbagai Rasio Reaktan

\begin{tabular}{cccccrrrrrr}
\hline \multirow{2}{*}{$\begin{array}{c}\text { Terpentin } \\
(\mathrm{mol})\end{array}$} & $\begin{array}{c}\text { Asam Asetat } \\
(\mathrm{mol})\end{array}$ & Rasio & \multirow{2}{*}{\begin{tabular}{c} 
Konversi \\
\cline { 5 - 10 }
\end{tabular}} & & \multicolumn{3}{c}{ Selektivitas (\%) } & \multicolumn{3}{c}{ Yield (\%) } \\
\hline 1 & 2 & 0,5 & 93,2 & & ester & isomer & alkohol & ester & isomer & alkohol \\
\hline 1 & 1 & 1 & 88,5 & 74 & 1,5 & 22,83 & 68,97 & 1,40 \\
2 & 1 & 2 & 95,8 & 14,5 & 83,8 & 1,7 & 14,85 & 79,32 & 1,63 \\
\hline
\end{tabular}

Reaksi asetosilasi merupakan reaksi esterifikasi yang umumnya bersifat reversible atau bolak-balik. Sesuai dengan prinsip Le Chatelier, jika salah satu reaktan dibuat berlebihan maka akan menggeser kesetimbangan reaksi ke arah produk sehingga akan didapatkan konversi yang lebih tinggi.

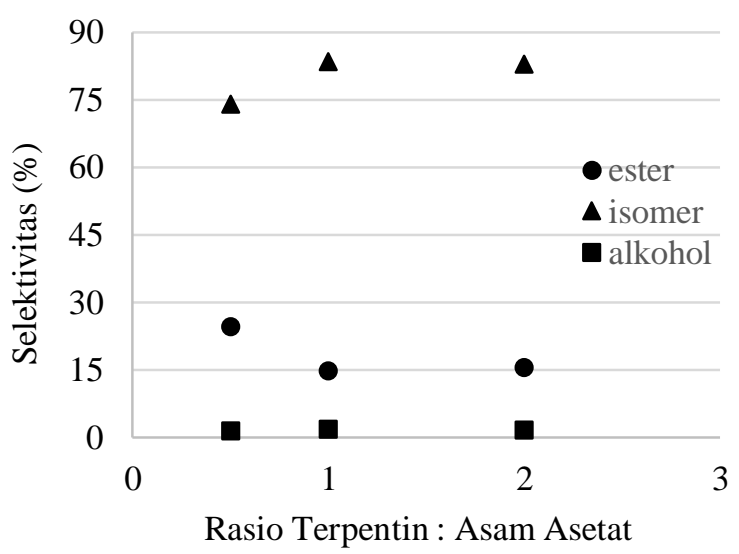

Gambar 6. Selektivitas Produk pada Berbagai Rasio Reaktan 
Dengan menggunakan asam asetat yang berlebihan, produk ester yang terbentuk juga menjadi meningkat. Keberadaan asam asetat yang melimpah memberikan lebih banyak kesempatan bagi molekul alfa pinen untuk bereaksi membentuk senyawa2 ester. Terpenil asetat menjadi hasil utama reaksi asetosilasi, diikuti dengan bornil asetat.

Pada rasio terpentin : asam asetat sebesar 2 , konversi alfa pinen meningkat menjadi 95,8\%. Namun selektivitas produknya hampir sama dengan reaksi dengan perbandingan stoikiometris. Hal ini mengindikasikan bahwa penggunaan terpentin secara berlebihan hanya menggeser kesetimbangan reaksi sehingga mempengaruhi konversi.

\section{Kesimpulan}

Terpentin dengan kemurnian $83,5 \%$ dapat direaksikan secara langsung dengan asam asetat tanpa melalui proses pemurnian awal. Reaksi menggunakan katalis asam sulfat dapat menghasilkan konversi yang hampir sama dengan yang dihasilkan oleh alfa pinen $98,5 \%$. Keberhasilan penggunaan terpentin secara langsung dapat mengurangi langkah pemurnian menggunakan distilasi vakum yang boros energi. Pada reaksi menggunakan asam asetat glasial, terjadi reaksi asetosilasi dan isomerisasi secara simultan. Sedangkan pada reaksi dengan larutan asam asetat juga terjadi reaksi hidrasi. Pada kedua kasus, katalis asam sulfat lebih mengarahkan reaksi pada reaksi isomerisasi.

\section{Daftar Pustaka}

Gainsford, G.J., Hosie, C.F., and Weston, R.J. (2001). Conversion of $\alpha$-pinene to terpinyl acetate over H-beta zeolites. Applied Catalysis A: General 209, 269-277.

Golets, M., Ajaikumar, S., Blomberg, D., Grundberg, H., Wärnå, J., Salmi, T., and Mikkola, J.-P. (2012a). Liquid phase acetoxylation of $\alpha$-pinene over Amberlyst-70 ion-exchange resin. Applied Catalysis A: General 435436, 43-50.
Golets, M., Ajaikumar, S., Larsson, W., Blomberg, D., Grundberg, H., Wärnla a, J., Salmi, T., and Mikkola, J.-P. (2012b). A Kinetic Study of the Liquid Phase Acetoxylation of $\alpha$ Pinene. Topics in Catalysis 55, 649656.

Grzona, L., Orejas, J., Volzone, C., and Ponzi, M.I. (2005). Kinetic modeling of alpha pinene catalytic transformation in liquid phase. (Rio de Janeiro), p.

Liu, S., Xie, C., Yu, S., Liu, F., Ji, K., and Xie, C.-X. (2008a). Esterification of $\alpha$ pinene and acetic acid using acidic ionic liquids as catalysts. Catalysis Communications 9, 1634-1638.

Machado, J., Castanheiro, J.E., Matos, I., Ramos, A.M., Vital, J., and Fonseca, I.M. (2012). SBA-15 with sulfonic acid groups as a Green Catalyst for the acetoxylation of a-pinene. Microporous and Mesoporous Materials 163, 237-242.

Masten, S., and Haneke, K. (2002). Turpentine: Review of Toxicological Literature of Turpentine Oil, Wood Turpentine, Sulfate Turpentine, Sulfite Turpentine (Integrated Laboratory Systems).

Robles-Dutenhefner, P.A., da Silva, K.A., H. Siddiqui, M.R., Kozhevnikov, I.V., and Gusevskaya, E.V. (2001). Hydration and acetoxylation of monoterpenes catalyzed by heteropoly acid. Journal of Molecular Catalysis A: Chemical 175, 33-42.

Román-Aguirre, M., Torre-Sáenz, L.D. la, Flores, W.A., Robau-Sánchez, A., and Elguézabal, A.A. (2005). Synthesis of terpineol from $\alpha$-pinene by homogeneous acid catalysis. Catalysis Today 107-108, 310-314.

Sastrohamidjojo, H. (2014). Kimia Minyak Atsiri. Yogyakarta: Gadjah Mada University Press.

Schwab, W., Fuchs, C., and Huang, F.-C. (2013). Transformation of terpenes into fine chemicals. European 
Journal of Lipid Science and Technology 115, 3-8.

Sidorenko, A.Y., Aho, A., Ganbaatar, J., Batsuren, D., Utenkova, D.B., Senkov, G.M., Warna, J., Murzin, D.Y., Agabekov, V.E. (2017). Catalytic isomerization of $\alpha$-pinene and 3-carene in the presence of modified layered aluminosilicate. Molecular Catalysis 443, 193 - 202.

Swift, K.A. (2004). Catalytic transformations of the major terpene feedstocks. Topics in Catalysis 27, 143-155.

Thiel, L., and Hendricks, F. (2004). Study into the establishment of an aroma and fragrance fine chemicals value chain (The Fund for Research into Industrial Development, Growth and Equity (FRIDGE)).

Utami, H., Budiman, A., Sutijan, R., and Sediawan, B.S. (2011). Heterogeneous Kinetics of Hydration of apinene for $\alpha$-terpineol Production: Non-ideal Approach. World Academy of Science, Engineering and Technology 80, 916-919.

Wijayati, N. (2016) Biotransformasi Alfa Pinena dari Minyak Terpentin. Semarang: Unnes Press.

Williams, C.M., and Whittaker, D. (1971). Rearrangements of pinane derivatives. Part II. Products of acidcatalysed rearrangement of alpha pinene and beta pinene in acetic acid. J. Chem. Soc. B 672-677.

Yadav, M.K., Patil, M.V., and Jasra, R.V. (2009). Acetoxylation and hydration of limonene and a-pinene using cation-exchanged zeolite beta. Journal of Molecular Catalysis A: Chemical 297, 101-109.

Yang, G., Liu, Y., Zhou, Z., and Zhang, Z. (2011). Kinetic study of the direct hydration of turpentine. Chemical Engineering Journal 168, 351-358. 